\title{
Embedding Outreach into the Undergraduate Science Curriculum - Everyone's a Winner
}

\author{
Helen C. Aspinall ${ }^{1 *}$, Anne Qualter ${ }^{2}$ and Elisabeth D. Rushworth ${ }^{3}$ \\ ${ }^{1}$ Department of Chemistry, ${ }^{2}$ Centre for Lifelong Learning, ${ }^{3}$ Central Teaching Laboratory \\ University of Liverpool, Liverpool, L69 3BX, U.K.
}

*Corresponding Author: hca@liv.ac.uk

Keywords: Employability, outreach, transferable skills

\begin{abstract}
This article summarizes the authors' experience of developing and delivering undergraduate modules in Science Communication. The modules address two needs: resourcing science outreach activities for children in Years 5-7, and developing transferable skills (oral and written communication, team working, time management) to enhance student employability and engagement.
\end{abstract}

\section{Introduction}

There are many good reasons why university science departments should be engaging in outreach work with their local schools.

"The primary and early secondary years of education represent a crucial phase in young people's development. Innately keen, curious and highly impressionable, this is when they are most receptive to exploring and learning about the world around them "(The Royal Society, 2010). The University of Liverpool, as one of the original civic universities, has its roots within the city and the local community, and there is a growing recognition of the importance of civic universities to their local communities.(Goddard, 2009; Munck, 2010; Powell \& Dayson, 2013) Like several other civic universities, the University of Liverpool is located in an area of high deprivation, and we envisaged that outreach with local schools could make a real contribution to the community. It is well-recognized that the impact of educational interventions is greater the earlier they take place (Barnett, 2011) and in this article we focus on our work with Years 5, 6 and 7 (aged 9 to 11). Although the importance of outreach with Years 5-7 is accepted, resourcing this activity is a major problem that must be addressed. Other university science departments (e.g. Bristol ChemLabs; Harrison et al., 2011; Harrison \& Shallcross, 2007) have reported on their outreach work with primary schools, but our approach is distinctly different in several respects. The approach we have adopted at Liverpool is to use undergraduate students to deliver Years 5-7 outreach as part of a 15credit module in Science Communication, available to students in Chemistry (CHEM390) and the Environmental Sciences (ENVS393). This article outlines the structure and delivery of the module and presents results from a case study of our work during 2014-15, demonstrating that both the school and the undergraduate students benefit from the approach.

\section{Structure and content of the module}

CHEM390/ENVS393 is a 15 credit Level 6 module and is available to students in Year 2 of a BSc or MChem programme or Year 3 of a BSc programme in Chemistry and to students in Year 3 (BA, BSc or MESci) or year 4 (MESci) of programmes in the School of Environmental Sciences. CHEM390 has been running for five years (since 2011-12), and is built on our 
experience of offering 'outreach' as an option for final year BSc Chemistry projects since 2006-7. ENVS393 was introduced in 2014-15 with the same module specification as CHEM390. CHEM390/ENVS393 run over two semesters: semester 1 covers generic topics and semester 2 focuses on detailed preparation and delivery of outreach sessions. During Semester 1, CHEM390 and ENVS393 students are taught together, which reduces the teaching load on academic staff, and means that this module can easily be extended to other subject areas across the Faculty of Science and Engineering (a module in Computer Science has been introduced for 2016-17). Due to the time constraints on delivery of sessions for school children (which all have to take place during the second half of semester 2), there is a limited capacity within a single subject area, and a typical cohort for each module is eight students. The modules are very popular and are always oversubscribed, which ensures that we can enroll the most highly motivated students, who are selected on the basis of personal statements and their records of reliability in other aspects of their work. As far as possible we assign them to years $5 / 6$ or year 7 according to their stated preferences. They work in pairs for the planning and delivery of sessions; each pair of students leads the delivery of two sessions (one 'practice' and one assessed), and supports the delivery of the other sessions. The lead pair of students is responsible for organizing their support team, and in this way all students gain a broad experience of team working.

Semester 2 A weekly three-hour session is timetabled throughout semester 2 , and in the first four weeks students make detailed preparations for delivery of their outreach sessions. This includes practising and timing of the practical activity (and making modifications where necessary), liaising with lab technicians to ensure that all necessary equipment and consumables are available, and preparation of a pupil workbook. Each week students are required to submit a brief report via the VLE, detailing the progress they have made and the tasks to be completed in the following week. This encourages them to take responsibility for planning and time management.

\section{Assessment:}

The assessed tasks are split across two semesters and are a combination of group assessment (GA) and individual assessment (IA) as shown in Table 2.

\begin{tabular}{|c|c|}
\hline $\begin{array}{c}\text { Semester } 1 \\
\text { Focus on generic topics }\end{array}$ & $\begin{array}{c}\text { Semester } 2 \\
\text { Focus on delivery }\end{array}$ \\
\hline $\begin{array}{l}\text { - } \text { Working with young people; safeguarding } \\
\text { - } \quad \text { Science teaching and the National Curriculum } \\
\text { - } \quad \text { Ussay writing skills } \\
\text { - } \text { activities } \\
\text { - Safety and risk assessments } \\
\text { - } \quad \text { Sesson-planning } \\
\text { visit sessions }\end{array}$ & 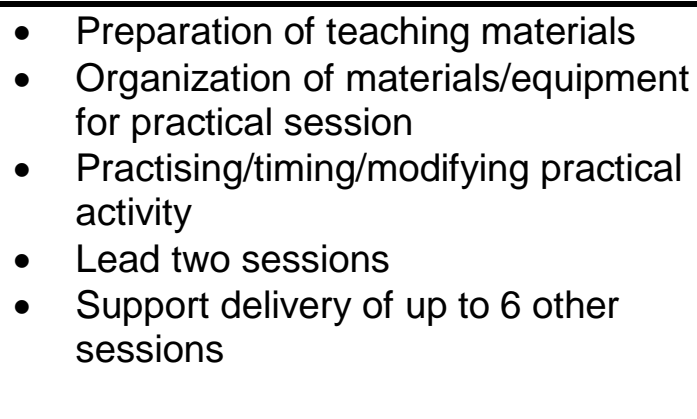 \\
\hline
\end{tabular}

Table 1 Summary of module content

\begin{tabular}{ll|ll}
\hline \multicolumn{1}{c|}{ Semester 1 } & \multicolumn{2}{c}{ Semester 2 } \\
\hline Essay (3000 words) (IA) & $20 \%$ & Delivery of sessions (GA) & $30 \%$ \\
Lesson plan/presentation (GA) & $10 \%$ & Dissertation (3000 words) (IA) & $30 \%$ \\
& & Poster (GA) & $10 \%$ \\
\hline
\end{tabular}

Table 2 Summary of assessment tasks 
A common set of grade descriptors is used for all assessments across CHEM and ENVS modules. The module leaders mark semester 1 essays and semester 2 dissertations, and consistency is ensured by the module moderator.

The session delivery and poster sessions are assessed by the module leaders and by academic staff who are not associated with the modules, and these marks are moderated. We find that academic colleagues enjoy attending the delivery and poster sessions and are happy to assist with these assessments.

\section{Semester 1 assessments}

The essay is broadly based on science teaching within the appropriate Key Stage, and the title is provided to the students e.g.: 'Consider current debates about the science curriculum and how this is influencing the emerging curriculum in primary/ secondary science'. Students are encouraged to explore questions (e.g. gender preferences for particular science topics) that they can address in questionnaires distributed to children at the outreach sessions. They have an opportunity to submit a draft of their essay and receive feedback before the final submission deadline. The lesson plan/presentation makes students think about delivering a coherent session with clear learning aims, context and links with the National Curriculum.

\section{Semester 2 assessments}

Students work in pairs to prepare the posters, and these are presented in a poster session at the end of the semester, where students have an opportunity to discuss their work with members of academic staff. Marks are assigned for the poster itself and for students' contributions to discussions at the poster session.

The dissertation is an individual piece of work where students reflect on the development and delivery of their outreach sessions, including a summary and interpretation of questionnaire responses. It can take the form of a reflective report or an action research report. As with the semester 1 essay, students have an opportunity to submit a draft of their dissertation and receive feedback. For Year 2 students this is usually the biggest written assignment that they have undertaken at university.

\section{Organization and delivery of the outreach sessions}

In the early years of CHEM390 we travelled out to schools to deliver primary outreach sessions, but this has several disadvantages: e.g. packing and transporting the equipment is time consuming, and facilities at the school are often unsuitable. Therefore all of our sessions are now delivered in the University of Liverpool's new Central Teaching Laboratories (opened in September 2012). This is an impressive venue, and the sheer scale of the building contributes to making the visit a really memorable occasion for the children.

The delivery schedule is determined by lab availability, student timetables and university/school term dates, and this limits the number of sessions that can be delivered in a single academic year. A cohort of eight students, working as four pairs, will deliver a total of eight sessions of approximately $1 \mathrm{~h} 45$ min each. These generally take place in the period between the school Spring half term in February and Week 11 of the University's semester 2. We can accommodate up to 30 children per sessions, and lab space is block booked for a 5-hour slot (9.00 to 14.00) each week. If necessary, two sessions can be delivered back-to-back on one day. Undergraduate classes are often in progress at the same time as the school visits, and sharing of lab space adds an extra dimension to the children's University experience.

The University's Widening Participation Team has an extensive Year 7 programme, in which students from Partner and Associate schools visit the university for a generic higher education aspiration-raising activity and an academic taster session. CHEM390/ENVS 393 provide the academic taster sessions for some of these visits. We arrange Year 5 and 6 visits directly with the schools; these are standalone science sessions with no generic content.

\section{Structure of the outreach}

\section{sessions}

CHEM390/ENVS393 students build their sessions around our extensive (and growing) 
menu of tried and tested practical activities (these have often been developed by Year 3 BSc project students). The students' original contribution is to prepare their own presentations and workbooks built around the theme of their chosen activity, identifying clear links with the National Curriculum. We purposely present the material in a 'university' style to give children a real experience of being outside their normal classroom environment.

The sessions open with an introductory presentation, putting the content of the experiment into the context of what the children already know, introducing and explaining technical language (e.g. 'polymer', 'hydrogel'), and briefly explaining the experimental procedure and lab safety rules. The children are provided with lab coats and safety glasses, and organized into pairs or larger groups as appropriate.

Instead of the session leaders giving instructions to the whole class, as would happen in school, we give the children workbooks and ask them to read the instructions for themselves and work out exactly what they need to do. This is usually a completely new experience for the children, but with support on hand from the team of students, they are able to develop some independence, often to the great surprise of their teachers.

The children are given a short evaluation questionnaire at the end of the session. In order to encourage students to think about pedagogical research, they design the questionnaire to address a research question that they raised in their Semester 1 essay e.g. an exploration of gender effects in children's attitudes to science.

\section{Content of the sessions}

We find that children in Years 5-7 have generally had very little experience of practical science, and what they have done has been presented in a 'whole-class' style with essentially no opportunity for independent working. We are able to give them a completely different experience: all of our activities require children to read and understand instructions, use basic lab equipment (e.g. measuring cylinders), make and record observations, discuss and interpret results. Some particularly popular and successful activities are:

\section{Year 5 \& 6 Chemistry}

Nappy Challenge: Children are given samples of the various components of a disposable nappy, and are asked to predict which component is the most absorbent. They then test each material using a measured sample of (fake) urine.

\section{Year 7 Chemistry}

Muddy water: Children are given a sample of extremely muddy water (sometimes including worms). They go through the processes of $\mathrm{pH}$ testing, aeration, coagulation, sedimentation, filtration and chlorination to produce a clear colourless sample of potable water (figure 1).

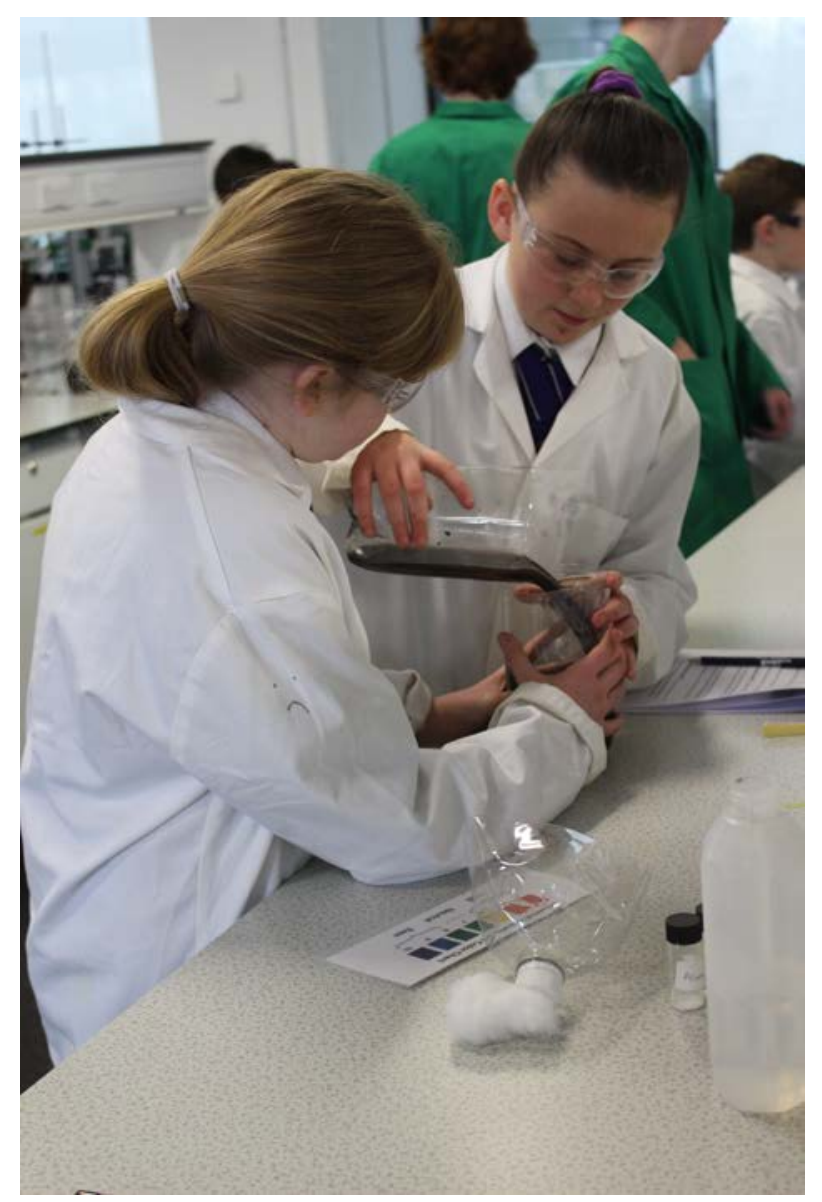

Figure 1 Year 7 students in the early stages of transforming muddy water into (almost) potable water.

\section{Year 5\&6 Environmental sciences}

Fossils, evolution and mass extinction: Children are asked to investigate the effects of asteroid impacts and volcanic eruptions on the 
Earth, how these effects might cause mass extinction events, and why some organisms don't die.

\section{Year 7 Environmental sciences}

Who Dunnit forensic geology: Children investigate how traces of sand can be used in the forensic sciences to track down a guilty person and find out Who Dunnit. They learn why there are different types of sand and use microscopes to investigate the shapes, sizes and colour of the sand grains. They then match the sand grains found on a group of suspects to those found on the murderer (figure 2).

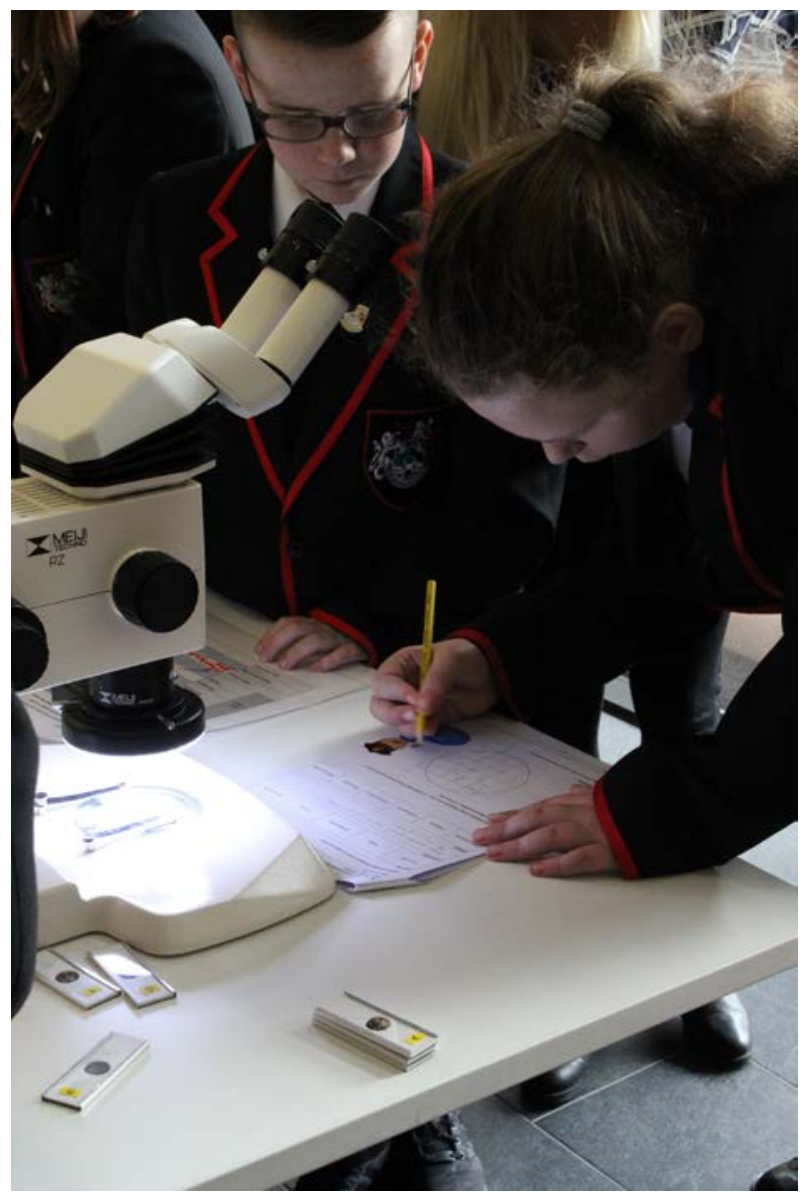

Figure 2 Year 7 students learning about forensic geology using microscopes to investigate sediment samples and discover who-dunnit!

\section{Impact on undergraduate student experience}

There has been considerable debate around exactly what is meant by 'employability', (Harvey, 2001; Knight \& Yorke, 2006) but there is general acceptance that in the world of work, graduates need more than just technical skills and knowledge (David et al., 2013). Reliability, ability to work in a team, written and oral communication skills, and time-management skills are key attributes that graduate employers value, and we set out when designing CHEM390 to address all of these key skills. In order to gain an insight into the impact on student experience (particularly with respect to transferable skills), the 2014-15 cohort of CHEM390/ENVS393 students were interviewed by one of us (AQ, who is not involved in assessment of the modules).

\section{Team-working}

Students clearly recognized that employers value the ability to work in a team:

\section{"whatever job, you need to work in a team"}

Most undergraduate science programmes now incorporate some elements of teamwork, but students were clear that the quality of teamwork experience in the Science Communication modules was of a different order from that normally encountered:

"people have been talking about team work and stuff and up to now it's just been pairs and stuff doing presentations in what we've done, but this is like a BIG method."

"in the past it's always just like 'you've got a week, make a poster, get

together...present this thing, or like write a report or something like that.' But with this you have got months ... and you really can have... a proper, independent, look at what you wanna do with it."

\section{"there's no person in it that doesn't try... everybody is involved, is doing, is contributing to the module."}

\section{Written and oral communication skills}

Science undergraduates (particularly in the physical sciences) usually start their university careers with little experience of essay writing. Extended writing rarely forms a major part of the first two years of a degree programme, so students are often ill-prepared for writing a dissertation in Year 3 or for entering work where report-writing is essential. Written assignments form a major part of the assessment for CHEM390/ENVS393, and 
students valued the experience that they gained from this:

"Because we had loads of modules that were basically exam based, I wanted to actually be able to write an essay and do other skills."

"it's as though you were almost writing your own research paper..."

Oral communication is at the heart of the delivery of the outreach sessions, and the students saw this as an opportunity to present science not just to an audience of children, but more generally to a different audience:

\section{"Improving your communication skills I think was one of the main things, like presenting to people that you wouldn't usually present to"}

\section{Time-management:}

The students take full responsibility for the planning and delivery of the sessions, working with lab technicians to ensure that all equipment and consumables are available, and organizing their peers into supporting roles as necessary. For many of them this is the first time that they have been responsible for seeing a project through from planning to delivery. They have really taken ownership of the project, understanding that the consequences of failure here are very different from the consequences of late submission of an assignment.

"Planning, getting organised is a big thing. If you don't get organised you haven't got anything to show the kids, It's not like you are going to be able to hand your essay in late."

"...you don't really have that in anything else do you? that you actually have to go and make sure everything, everything is ticked off by a certain time"

\section{General comments on key skills:}

It can often be difficult to persuade students of the value and relevance of key skills modules, but we found that the context of the Science Communication module was an ideal vehicle for teaching key skills: "this is different, completely different, because it's probably more relevant than our key skills module where you have to write an essay or do a presentation because it is like, over a whole year you are ... on a project as if it was a job."

"Its been a good module because we have managed to do something helpful, because we have been able to teach the kids, and, obviously a good thing has come out of it and there's been loads of transferable skills"

\section{Support for PGCE (post graduate certificate in education) and job applications:}

Students who have taken CHEM390 and ENVS393 have had $100 \%$ success rate in getting on to their first choice PGCE course or other graduate teacher-training scheme, and they feel that the module has contributed to their success:

"the teaching experience itself is really useful because I have been applying for teaching jobs and I have included this in my applications and at my interviews they were all really keen to ask about why I chose it and what I have gained out of it"

Those who have chosen to progress to careers other than teaching also feel that they have gained skills that will differentiate them from other candidates.

"...but with (CHEM)390, it's giving you that extra edge that I think a lot of candidates wouldn't have."

\section{Some unexpected benefits}

Students identified other benefits that we hadn't anticipated, and which contributed to their enjoyment of their university experience in general.

"I think it brings you back into interest in your subject as well."

"I think it's also, we have not mentioned it really, but getting to know your lecturers as people" 
Embedding Outreach into the Undergraduate Science Curriculum - Everyone's a Winner

"...having this has definitely made my time more enjoyable because I am getting quite sick of doing lectures every day."

\section{Impact on the schools and children}

Although as scientists we are obviously keen to enthuse children about our subjects, our intention has been to have a wider impact on children's experience. Aspiration raising activities have been shown to have marginal impact and there is evidence that it is lack of attainment rather than lack of aspiration that prevents some disadvantaged children from fulfilling their potential (Archer et al., 2013). We aim to stretch and challenge children rather than simply entertain them, and we know that the primary schools that take part in our outreach activities do follow-up work in school after their visits, for example reports on the school blog. Teachers at our longest standing partner primary school told us that language was their biggest challenge, and when asked about the biggest impact of our science outreach work, they identified (somewhat to our surprise) language skills:

"Last year when we came back, there was just so much talk and discussion between themselves that.... I'll use [name] as an example then. We first went to the University I think it was about February time. Before we went she hardly spoke, and then that day I saw a massive change in her language - she was talking to her friends, she was discussing - and I think the biggest impact from last year was that. Speaking and listening skills."

Year 6 children from the same school were able to describe in detail how they had made 'mayonnaise' on a visit in Year 5, and what it looked like through a microscope:

\section{"They looked like little tiny little things moving around"}

"Like the little bacteria and stuff"

This shows that our outreach work can have some unexpected positive impacts, and a detailed case study of our work with one local primary school will be published separately.

\section{Lessons learned}

The high level of student motivation has contributed enormously to the success of the science communication modules. This has been achieved and maintained by making the modules selective: students have to submit a one-page personal statement as part of the application process, and they must have good prior records of attendance and meeting deadlines in order to be accepted. Typically, half of the applicants are rejected, and the successful applicants inevitably feel quite special, which further increases their motivation. The modules are classed as Level 6 , and so it is essential to explain clearly to Year 2 students that the demands made on them will be significantly higher than in a typical Level 5 module. Students have been happy to accept this because they see that they will benefit from development of their transferable skills. The major organizational task is setting up school visits, and arrangements need to be in place several weeks or months ahead of the visit in order to ensure that all necessary permissions are in place; good relationships with school staff are essential in order to achieve this. Half of the assessment for the modules is based on joint work from pairs of students, and this may occasionally lead to friction if there is a perception that students have not contributed equally. It is therefore wise to have a mechanism in place to allow an appropriate distribution of marks.

\section{Conclusions}

We have developed a sustainable model for delivery by undergraduate students of science outreach to children in years 5-7. Teachers value the science content of the sessions, but have also identified wider impacts on the children's general education, particularly language development. Visits to the University labs have a considerable impact on the children, who, over 12 months later, are able to remember details of their visits. Undergraduate students who take the outreach modules benefit through gaining in confidence as well as acquiring valuable transferable skills. The outreach sessions that they deliver as part of the modules make a useful contribution to the University's Access Agreement targets, and most of the students continue to make a valuable contribution to our outreach activities. There is a high rate of progression from 
CHEM390 to PGCE and students usually get onto their first choice course.

\section{References}

Aspiration interventions Toolkit references [Online]. Education Endowment Foundation. Available:

https://educationendowmentfoundation.org.uk/ uploads/pdf/Aspiration interventions Toolkit References.pdf [Accessed 22 ${ }^{\text {nd }}$ August 2016].

Deprivation Mapper [Online]. OpenDataCommunities.org. Available: http://opendatacommunities.org/showcase/de privation [Accessed 22 ${ }^{\text {nd }}$ August 2016].

Archer, L., DeWitt, J. \& Wong, B. (2013). Spheres of influence: what shapes young people's aspirations at age 12/13 and what are the implications for education policy? Journal of Education Policy, 29, 58-85. DOI: 10.1080/02680939.2013.790079

Barnett, W. S. (2011). Effectiveness of early educational intervention. Science, 333, 975-8. DOI: 10.1126/science.1204534

David, J. F., Leah, K. H., Riley, B. \& Mark, Z. (2013). An exploratory study of factors affecting undergraduate employability. Education + Training, 55, 681-704. DOI: 10.1108/ET-07-2012-0077

Goddard, J. (2009). Re-inventing the civic university. NESTA.

Harrison, T. G., Hanford, K. L., Cheesman, B. T., Kaur, G., Franklin, S. D., Laurain, A. M. C.,
Medley, M. I., Rivett, A. C., Shallcross, K. L., Shaw, K. E., Williams, S. J., Shallcross, D. E. \& Sellou, L. (2011). The many positive impacts of participating in outreach activities on postgraduate students. New Directions, 13-17. DOI: 10.11120/ndir.2011.00070013

Harrison, T. G. \& Shallcross, D. E. (2007). Why Bother Taking University Led Chemistry Outreach into Primary Schools? Bristol ChemLabS Experience. New Directions, 4144. DOI: 10.11120/ndir.2007.00030041

Harvey, L. (2001). Defining and Measuring Employability. Quality in Higher Education, 7, 97-109. DOI: 10.1080/13538320120059990

Knight, P. T. \& Yorke, M. (2006_. Employability: judging and communicating achievements. Learning and Employability Series 1. York, U.K.: The Higher Education Academy.

Munck, R. (2010). Civic Engagement and Global Citizenship in a University Context: Core business or desirable add-on? Arts and Humanities in Higher Education, 9, 31-41. DOI: $10.1177 / 1474022209350102$

Powell, J. \& Dayson, K. (2013). Engagement and the idea of the civic university. University Engagement With Socially Excluded Communities. Springer.

The Royal Society. (2010). Primary science and mathematics education: getting the basics right. 